\title{
Introducing transapical aortic valve implantation (part 2): Institutional structured training program
}

\author{
Miralem Pasic, MD, PhD, Axel Unbehaun, MD, Stephan Dreysse, MD, Semih Buz, MD, \\ Thorsten Drews, MD, Marian Kukucka, MD, Alexander Mladenow, MD, Roland Hetzer, MD, PhD, and \\ Giuseppe D'Ancona, MD, PhD
}

Objectives: Introduction of a new procedure has a typical learning curve with the "learning phase" at the begin-
ning, characterized by an increased mortality or complication rate. We developed our institutional structured train-
ing program for transcatheter aortic valve implantation (TAVI) with the aim of eliminating these negative effects.

Methods: The program regulated the introduction of TAVI and building and training of the team. It combines cumulative knowledge from the field with the institutional and individual background experience. It includes stepwise acquisition of the tools necessary for the preoperative strategic planning, perioperative team communication, technical aspects of the procedure, and postoperative management. The program establishes a basis for interaction and feedback between the members of the team ("teach and learn"; "be proctor and proctored").

\begin{abstract}
Results: The program consists of 4 main parts: general principles, team building, team education and training, and the institutional clinical and procedural policies. The program possesses several control mechanisms, eg, occasional external proctoring. Additionally, a chain of steps spontaneously generates further procedural improvements and optimizes the overall outcome. The program has also had a global positive effect on the local institutional environment, awaking awareness of existing latent conditions and active failures, identifying them and inducing their correction, which has led to general clinical improvement.
\end{abstract}

Conclusions: A structured educational training program enables implementation of a new procedure (TAVI) into clinical practice without increased morbidity and mortality rate during the learning curve. The program may also be used as a basis for any new device introduction into clinical practice. (J Thorac Cardiovasc Surg 2013;145:919-25)

Implantation of a biologic prosthetic valve in the aortic valve position by a catheter, called transcatheter aortic valve implantation (TAVI), has its experimental roots in 1965 when Davies ${ }^{1}$ put a valve mounted on a catheter into a descending thoracic aorta. The basic experimental work in this field done by Andersen and colleagues ${ }^{2}$ and published in 1992 enabled later clinical application of TAVI beginning in 2002..$^{3-5}$ This long-lasting pioneering path of different individuals and institutions resulted in enormous cumulative knowledge that has led to fast introduction of TAVI in a number of centers worldwide. TAVI is currently a broadly established treatment method with different types of valves used (self-expandable, balloon expandable) and the different possible ways of implantation (transfemoral, transapical, transaxillary, transaortic).

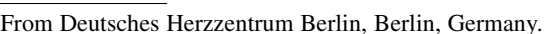

Disclosures: M.P., A.U., S.D., S.B., and T.D. have been proctors to Edwards Lifesciences since July 2009. All other authors have nothing to disclose with regard to commercial support.

Received for publication May 16, 2012; revisions received Nov 2, 2012; accepted for publication Dec 12, 2012; available ahead of print Feb 4, 2013.

Address for reprints: Miralem Pasic, MD, PhD, Deutsches Herzzentrum Berlin, Augustenburger Platz 1, 13353 Berlin, Germany (E-mail: pasic@dhzb.de). $0022-5223 / \$ 36.00$

Copyright (c) 2013 by The American Association for Thoracic Surgery http://dx.doi.org/10.1016/j.jtcvs.2012.12.085
}

Transapical TAVI is a more difficult technique than transfemoral implantation and requires a longer learning curve. ${ }^{6}$ It is a "procedure of 1001 details," a series of small sequences that need to be performed precisely, in perfect order, and with perfect timing and excellent coordination between the members of the team. ${ }^{7}$ It combines both precise surgical technique and interventional skills, and therefore departs from standard surgical policies and requires new ways of thinking. ${ }^{6}$ Failure in a single sequence may produce a disastrous situation with dangerous and life-threatening complications. ${ }^{7}$

The clinical application of TAVI program was started at Deutsches Herzzentrum Berlin in April 2008 and introduced according to our intensive and structured program for the building, education, and training of the team. We report our institutional structured training program for TAVI. ${ }^{6-24}$

\section{MATERIALS AND METHODS}

The institutional training program regulates the introduction of the TAVI procedure at the Deutsches Herzzentrum Berlin (Berlin, Germany). It was developed by a senior team member (M.P.) commissioned to introduce and establish TAVI at Deutsches Herzzentrum Berlin. The program consists of 4 main parts: (1) general principles, (2) team building, (3) team education and training, and (4) the institutional clinical and procedural policies.

\section{GENERAL PRINCIPLES}

1. TAVI should be validated as a safe and reliable procedure. 


\section{Abbreviations and Acronyms}

$\mathrm{CPB}=$ cardiopulmonary bypass

LVEF = left ventricular ejection fraction

LVOT $=$ left ventricular outflow tract

MSCT $=$ multislice computed tomography

TAVI $=$ transcatheter aortic valve implantation

TEE $=$ transesophageal echocardiography

2. TAVI should, from the beginning of the learning curve, match the results of the already established method (conventional aortic valve replacement) applied in the same patient population at Deutsches Herzzentrum Berlin.

3. The technical provisions in terms of a special hybrid operating room that combines a catheter laboratory should provide the preconditions necessary to perform surgery and sterile valve preparation before implantation, anesthesiologic equipment, appropriate lighting, and the heart-lung machine.

4. The TAVI team should be built, educated, and trained on the basis of contemporary knowledge and general institutional experience.

5. The TAVI team should be trained to perform all types of TAVI, including the management of the possible procedural complications.

6. Before every implantation, the team should analyze the patient's characteristics, analyze the possible course of the procedure and possible complications, and identify how to act in the particular situation.

7. After every implantation, the team should analyze the course of the procedure and complications and identify possible weak points of the procedure and possible procedural improvements.

8. Institutional clinical and procedural polices should be established and regularly updated.

9. The whole process of the TAVI procedure should be uniform and should comply with the established institutional practice.

10. A separate TAVI data bank should be established.

11. Treatment of patients undergoing TAVI should be organized as a chain from the beginning to the end of hospitalization and in the outpatient follow-up.

12. The TAVI program should be organized to be able to provide the institutional service 24 hours per day.

13. The TAVI program, including the technical preconditions and safety of the new procedure, the technical part of the procedure and the clinical results, should be continuously monitored, documented, analyzed, and improved.

14. The above principles should be complied with; otherwise the program should be redefined.

\section{BUILDING OF THE TEAM}

The institutional team consists of 2 parts: the core team and the virtual team. The core team comprises 2 anesthesiologists with expertise in transesophageal echocardiography (TEE), 5 surgeons of 4 different surgical generations, and 2 experienced cardiologists. The virtual team consists of approximately 50 persons involved in the chain of treatment of patients undergoing TAVI from the beginning to the end of hospitalization and in the outpatient follow-up. Representatives of the valve manufacturing companies are considered to be members of the virtual team. The persons in the virtual team should not necessarily be known to be involved in the virtual team.

\section{EDUCATION AND TRAINING}

1. Review of the contemporary cumulative knowledge from the field.

2. Theoretic procedural preparation.

3. Training on a computer simulator.

4. Training by dry runs.

5. Visits to teaching centers with live procedural case demonstrations.

6. Repeated proctoring by external experts.

7. Internal proctoring by the members of the team themselves.

8. Visits to other colleagues and exchange of experience.

9. Attendance at scientific meetings with presentation of the institution's own experience.

10. Publication of results and experience.

11. Continuous review of the new literature.

12. Live broadcasting of the teaching cases.

13. Helping other colleagues to establish their own programs (proctors for the manufacturers of the valves).

14. Cooperation with other cardiologists from the region.

15. Fellowships for guest doctors.

16. Cooperation with industry.

There were 2 modes of proctoring: external and internal. The external proctoring was performed by experts in the field who were from different centers. External proctoring was applied for the first cases by the pioneering experts depending on the type of TAVI procedure. Later on, this was continued by occasional and repeated visits from other experts with the aim to exchange experience, to improve the details of the procedure, and to identify possible invisible or systemic errors that might be inherent in the TAVI process. The internal proctoring was managed as a self-appraisal relationship with regard to surgical experience between the members of the team where opinions were exchanged in an open discussion during the evaluation of the TAVI processes. Principally, if there were 2 or more similar alternatives, the suggestion 
chosen was always that of the youngest member in the team. This established a basis for interaction and feedback between the members of the team ("teach and learn"). Each member had full freedom in decision-making and in performing the procedure in accordance with the institutional policies for TAVI established by the team itself. The internal proctoring was basically performed by the most experienced surgeon/cardiologist ("senior proctors") and then gradually taken over by other members of the team ("younger proctors"), according to their surgical experience, who were taught to allow interactive proctoring ("be proctor and proctored"). During the initial internal phase, the senior proctors performed all procedures if complications were expected because of patients' clinical condition (eg, poor left ventricular ejection fraction [LVEF], cardiogenic shock, age $\geq 90$ years, special situations).

The internal proctoring was divided into 4 segments and aimed at achieving complete understanding and independence in the various phases of the TAVI process.

Segment 1 consisted of proctoring of preoperative patient evaluation and determination of the indication in general.

Segment 2 was performed in the hybrid operating room immediately before the procedure. It included proctoring the analysis of the patient's preprocedural evaluation, multislice computed tomography (MSCT) and echocardiographic annulus assessment, valve size determination, and analysis of possible procedural problems. In this phase, the "trainee" should acquire the knowledge to adequately measure the size of the aortic annulus mainly by means of TEE and be able to determine it by him/herself. Appropriate valve selection, on the basis of the global aortic anatomy and the patient's characteristics, was the most important final goal of segment 2 .

Segment 3 consisted of 2 different parts: proctoring of valve preparation and crimping followed by proctoring of the technical parts of the procedure itself.

The first part was propaedeutic to the second part, and each member of the team had to achieve full knowledge of the disposable materials and full independence in valve preparation before starting with the technical parts of the procedure itself.

The second part of segment 3 included an early ("assistant") phase and a late ("first operator") phase for the trainee. During the "assistant phase," the trainee would become familiar with the various steps of the procedure and focus on some simple but focal tasks, such as maintaining the transapical introducer and stiff guidewire position during manipulation and catheter insertion/removal, air purging, and correct timing for contrast agent injection during the controlled valve release. Coordination with the operator to minimize left ventricular apical bleeding during insertion and removal of the large-bore introducers was also practiced during this phase. In preparation to the "operator phase" of segment 3 , the trainee was also required to learn by heart and recite with the correct emphasis the standardized commands given during the implantation phases of the procedure by the operator (Tables 1 and 2). Commands need to be clearly stated to alert the other team members to the various phases of aortic valvuloplasty and prosthesis implantation.

The "operator phase" of segment 3 was performed in 5 periods (A-E) and includes active and passive proctoring. In period A, the internal proctor is scrubbed and is in the team performing the procedure, either on the same side as the operator or on the opposite side. During this phase, the trainee will progressively acquire the necessary knowledge to perform independently the various phases of the procedure. Initially, emphasis will be given to the identification of the correct site to perform the thoracotomy to minimize the trauma and optimize the access to the ventricular apex, appropriate selection of the left

TABLE 1. Checklist during transapical transcatheter aortic valve implantation

1. Puncture of ventricular apex

2. Passage of guidewire through valve

3. Small-bore introducer (14F) through valve

4. Exchange of standard guidewire with stiff guidewire

5. Passage of valvuloplasty balloon through the valve

6. Preparation of the external pacemaker

7. Disconnection of the ventilation tube from the ventilator

8. Activation of the pacemaker at 160 beats/min

9. Output is reduced

10. Balloon inflation

11. Contrast injection (before full inflation of the valvuloplasty balloon)

12. Balloon deflation

13. Discontinuation of the external pacing

14. Reconnection of the ventilation tube to the ventilator

15. Removal of small-bore introducer

16. Insertion of large-bore $(24 \mathrm{~F}$ or $26 \mathrm{~F})$ introducer

17. Valve forwarding through introducer

18. Deaeration of the introducer system

19. Removal of valve pusher

20. Contrast injection (for initial selection of adequate valve position)

21. Preparation of the external pacemaker

22. Disconnection of the ventilation tube from the ventilator

23. Activation of the pacemaker at 160 beats/min

24. Output is reduced

25. Contrast injection (to confirm position)

26. Balloon inflation

27. Contrast injection (for fine correction of valve position)

28. Balloon complete inflation (and count "21-22-23")

29. Balloon deflation

30. Discontinuation of the external pacing

31. Reconnection of the ventilation tube to the ventilator

32. Balloon retraction within introducer

33. Note the recovery (or absence) of the heart function

34. Retract the introducer, balloon-catheter, and the super-stiff guidewire

35. Close the apex 
TABLE 2. Command list* during transcatheter aortic valve implantation (corresponding to Table 1)

1. Apical puncture!

2. Guidewire is coming!

3. $14 \mathrm{~F}$ introducer is coming!

4. (no command) (exchange of standard guidewire with stiff guidewire)

5. Valvuloplasty balloon is coming!

6. Pacemaker ready?

7. Disconnect the tube!

8. Pacemaker on! 160! (if necessary, additional command: pacemaker 180 !)

9. No output!

10. Balloon inflation!

11. Angio! (Contrast injection before full inflation of the valvuloplasty balloon)

12. Balloon deflation!

13. Pacemaker off!

14. Reconnect tube!

15. $14 \mathrm{~F}$ introducer is coming out!

16. $26 \mathrm{~F}$ (or $24 \mathrm{~F}$ ) introducer is coming!

17. Valve is coming! (alert to valve introduction)

18. No command (deaeration of the introducer system)

19. Pusher backward!

20. Angio! (contrast injection for initial selection of adequate valve position)

21. Pacemaker ready?

22. Disconnect tube!

23. Pacemaker on! 160! (if necessary, additional command: pacemaker 180 !)

24. No output!

25. Angio! (Contrast injection to confirm position)

26. Balloon inflation!

27. Angio! (Contrast injection for fine correction of valve position)

28. No command (after complete balloon inflation count loudly: "21-2223")

29. No command (balloon deflation)

30. Pacemaker off!

31. Reconnect tube!

32. No command (balloon retraction within introducer)

33. Is recovering! (note the recovery [or absence] of the heart function)

34. No command (pull back and retract the introducer, balloon-catheter, and super-stiff guidewire)

35. No command (information if there should be problems with closure of the apex)

*Commands should be learned by heart during the "assistant" phase of the training and given only by the operator, loudly and clearly. They serve to guide and coordinate the entire TAVI team during the various phases of the procedure.

ventricular entry point, and correct placement of the ventricular purse-strings. In a second stage, the trainee will familiarize him- or herself with transapical puncture, guidewires and introducer passage, and valve positioning and release. In period $\mathrm{B}$, once the trainee has acquired the necessary skills to perform the various steps, the internal proctor is in the hybrid operating room and is scrubbed but does not assist in the procedure. In period $\mathrm{C}$, the internal proctor is in the hybrid operating room but is not scrubbed and not active at the operating field.
In period $\mathrm{D}$, the internal proctor is in the operation tract but not in the hybrid operating room. The last period of segment 3 is period E, the "no-proctoring" phase where the trainee has fully acquired and developed all the necessary skills to perform the various stages of the procedure independently.

Segment 4 consists of proctoring of the evaluation of the procedure and the postprocedural patient management.

\section{INSTITUTIONAL CLINICAL AND PROCEDURAL POLICIES}

The institutional policies contain the guidelines on how to act in particular situations with regard to patient selection, procedural steps, and complications. ${ }^{6-24}$ They are now updated as of December 2011.

1. Indications: The patients can be evaluated and accepted for TAVI according to the contemporary accepted criteria after comparison with the present institutional practice. The patients who do not fulfill the criteria may be accepted for TAVI for technical surgical reasons (eg, porcelain aorta) or because of a very high risk for conventional operation due to factors not covered by the risk scores (eg, liver cirrhosis, malignancy, or in special situations such as in patients with assist devices). The reason or reasons must be widely acceptable and clearly formulated and documented.

2. "No exclusion" policy: All very high-risk patients, including those with poor LVEF $(10 \%-20 \%)$ or cardiogenic shock or those requiring a rescue procedure, should be considered for TAVI (except those with endocarditis or too large annuli). No patient should be refused because of comorbidities.

3. Contraindications: The absolute contraindications for TAVI are active or recent endocarditis or an annulus size that exceeds the recommendations of the valve manufacturers.

4. Assessment of the device landing zone (left ventricular outflow tract [LVOT], annulus, cusps, sinuses of Valsalva, proximal aorta): The annulus is assessed preoperatively using transthoracic echocardiography (parasternal long-axis view) and MSCT (coronal and sagittal views), and immediately before TAVI by TEE (mid-esophageal short and long-axis view; [for the measurement of the annulus diameter: long-axis view during the maximal diameter of LVOT in midsystole]). The reference level is set immediately below the insertion of the cusps ("subannularly"). In the hybrid operating room, immediately before TAVI, the diameter of the annulus is measured first by our TAVI anesthesiologist(s) with expertise in TEE and then by the surgeon(s) and the cardiologist designated for the particular procedure, while the numeric values are hidden ("blinded fashion"). Next, the results are revealed 
and one value is defined as the "reference value." In general, the transthoracic echocardiography result is used only as an orientational value for screening if the annulus is too large for the use of the contemporary transcatheter valves.

In particular, the following measurements are performed (TEE or MSCT): diameters of the LVOT, annulus, and aorta (at the levels of the sinuses of Valsalva, sinotubular junction, and mid-ascending aorta), distances between the coronary artery ostia and the aortic annulus, distances between the commissures themselves, distances between each commissure and the aortic wall of the opposite sinus of Valsalva. The measurements are performed in conjunction with the evaluation of the morphology of the heart and aorta, determination of the projection of the left ventricular apex to the anterior chest wall, and identification of the shapes of the annulus ("round" vs "oval") and proximal aorta (whether the sinuses of Valsalva are pronounced or not in comparison with the mid-portion of the proximal aorta; "maleshaped" vs "female-shaped"). Specific pathologies influencing the valve-size selection, the procedure and valve positioning (eg, localized calcified masses, open or fused commissures), and amount of calcification in the neighborhood of the commissures are identified. The number of open or fused commissures is counted (0 to 3 ), and the amount of calcification in the device landing zone is assessed semiquantitatively by visual estimation (grade 0 to +++ ).

5. Selection of the valve size: Principally, the size of the valve used is determined according to the diameter of the native aortic valve annulus measured by intraoperative TEE ("reference value"). In general, a 2-mm oversized valve is used; the 23-mm Edwards Sapien prostheses (Edwards Lifesciences, Irvine, Calif) are applied for the aortic annuli with a diameter of less than $21 \mathrm{~mm}$, and the 26-mm Edwards Sapien prostheses are applied for annuli with a diameter of 21 to 24 $\mathrm{mm}$. For annuli greater than $24 \mathrm{~mm}$ and $27 \mathrm{~mm}$ or less, a 29-mm Edwards Sapien XT valve (balloon expandable) is used. For the larger annuli ( $>27 \mathrm{~mm}$ and $\leq 29 \mathrm{~mm}$ ), a 31-mm CoreValve (CoreValve Revalving System; Medtronic Inc, Minneapolis, Minn) (transfemoral or transaxillary approach) should be applied or conventional aortic valve replacement reconsidered (with cardioplegic arrest if an aortic crossclamp time of $\sim 20$ minutes is predicted to be possible, otherwise on the beating heart using retrograde heart perfusion through the coronary sinus). (Before a 29-mm Edwards Sapien XT prosthesis was available, for the annuli between 24 and $27 \mathrm{~mm}$, we used self-expandable 29-mm CoreValve prostheses [transfemoral or transaxillary approach].)
In borderline cases, when measurements ranged around $21 \mathrm{~mm}$ (24 mm, respectively), MSCT influenced the valve size selection. In this case, the decision on valve size was made on an individual basis, taking into account all additional factors, such as the distances from the annulus to the coronary artery ostia, the shape of the annulus (oval vs circular), the amount of material in the leaflets, the aortic diameters at the level of the sinuses of Valsalva, the sinotubular junction and ascending aorta, and the amount of calcification in the LVOT, anterior mitral leaflet, commissures, and aortic valve leaflets themselves. In borderline cases, the factors that suggest a smaller valve (and vice versa for a larger prosthesis) are narrow aortic root with nonpronounced sinuses of Valsalva ("male-shaped" aorta), round shape of the aortic valve annulus, pronounced or severe calcification of the device landing zone, fused commissures (with 0-1 open commissure), short $(<8 \mathrm{~mm})$ distance between the annulus and the coronary artery ostia, female gender of the patient, and body surface area less than $1.8 \mathrm{~m}^{2}$.

6. Use of femoro-femoral cardiopulmonary bypass (CPB): Elective normothermic femoro-femoral CPB should be considered in patients with low LVEF (10\%-20\%), cardiogenic shock or rescue procedure, and significantly enlarged right ventricle with poor right ventricular ejection fraction and severe pulmonary hypertension. CPB (femoro-femoral normothermic $\mathrm{CPB}$ ) is used to stabilize the patients' condition, to achieve hemodynamic stability during TAVI, and to prevent possible manual cardiopulmonary resuscitation if ventricular fibrillation should occur during rapid pacing for balloon valvuloplasty and during valve deployment. In patients with cardiogenic shock, CPB is used for additional myocardial recovery of the unloaded heart after the new transcatheter valve is deployed.

7. Prophylactic use of intra-aortic balloon pump: An intra-aortic balloon pump should be considered in patients with poor LVEF $(10 \%-20 \%)$ and in patients in cardiogenic shock.

8. Valve deployment: Precise deployment of the new valve in the desired position should be performed by slow and gradual inflation of the balloon under visualization of the aortic root structures by simultaneous angiography through a pigtail catheter placed in the proximal ascending aorta above the new valve.

9. Simultaneous treatment of combined coronary artery disease: Simultaneous elective percutaneous coronary intervention, or coronary artery bypass grafting if percutaneous coronary intervention is not possible, is considered in patients with concomitant coronary artery disease. Only the most relevant coronary artery stenosis is treated. 
10. "Valve-in-valve" concept for degenerated biological valve prosthesis: This concept may be considered in high-risk patients as a therapeutic or a palliative approach.

11. Combined atrioventricular valve pathology: Concomitant significant functional atrioventricular valve pathology is not treated in combination with TAVI, but later on by conventional surgery, if necessary. The exception is tricuspid valve regurgitation of grade IV.

12. Post-implant paravalvular leakage or transvalvular regurgitation: Aortic regurgitation after valve implantation of grade 1 to 2 (or greater than grade 2) should be treated by additional balloon dilation of the valve and, if necessary, by implantation of a second valve. In the case of grade 2 or greater, if it is not correctable, conventional surgical aortic valve replacement should be considered.

13. Intraprocedural bleeding of unknown origin: Any arterial bleeding with no identifiable cause should be considered as suspected annulus rupture, and therefore immediate institution of CPB and a median sternotomy should be performed to treat it, even in patients who are considered formally "inoperable" or "not suitable for conventional surgery." Standard aortic valve replacement should be performed, and in the case of myocardial rupture, the LVOT should be reconstructed with an oversized pericardial patch. No attempts should be made to close the rupture of the left ventricle from the outside.

14. Slow myocardial recovery: Patients with poor left ventricular function (LVEF 10\%-20\%), cardiogenic shock, or an enlarged right ventricle and pulmonary hypertension are prone to the intraprocedural complications (mostly slow recovery of the myocardial function immediately after balloon dilatation of the valve or valve deployment). In this situation, repeatedly administer additional increased doses of catecholamine (medicamentous reanimation) through the central venous catheter or even give them directly into the aortic root via pigtail catheter. Consider use of CPB (femoro-femoral). Consider and exclude (by TEE = short axis view, angiography) iatrogenic obstruction of the coronary artery ostia or rupture of the aortic root structures. Consider possible coronary artery (micro)embolization.

15. Special situations: TAVI can be considered but very cautiously accepted in patients with bicuspid aortic valve, previous mitral valve replacement or homograft implantation, and with left ventricular assist devices who have pure aortic valve insufficiency.

16. TAVI combined with conventional surgery: TAVI can be combined with conventional heart surgery for complex heart pathology.

\section{CONCLUSIONS}

Our institutional structured educational and training program combines cumulative knowledge from the field with the institutional and individual background experience. It is applied consecutively as an interactive self-proctoring of the team during the later period ("be proctor and proctored"). The aim of the program is to implement TAVI safely and efficiently into clinical practice with the intention not to increase the morbidity and mortality rate during the learning curve.

The program possesses several control mechanisms, for example, occasional external proctoring. In addition, a chain of steps spontaneously generates further procedural improvements and optimizes the overall outcome. For example, one of the main steps of the program is the obligation to publish our own results. ${ }^{6-24}$ This requires a review of the contemporary literature (thus increasing the individual and the team knowledge and giving new ideas), includes self-evaluation of the results (thus enabling additional identification of the failures and increasing awareness of them), forces us to make comparison between our own and other centers (additionally increasing awareness of failures, need for self-criticism, and desire for improvements), and generates positive competition between the members of the team themselves, enhancing their self-esteem (and thus stimulating prospective publications). It should also be mentioned that the structured program has had a global positive effect on the local institutional environment, awaking awareness of existing latent conditions and active failures, ${ }^{25}$ identifying them, and inducing their correction, which has led to general clinical improvement. The program also may be used as a basis for any new device introduction into clinical practice.

The other members of our TAVI team are Christoph Klein, MD, Ekatarina Ivanitskaia-Kühn, MD, Guna Tetere, MD, Tom Gromann, MD, Katrin Schäfer, and Natalia Solowjowa, MD. The authors thank Anne Gale for editorial assistance and Rosemarie Günther for secretarial support. Special thanks to Edina Pasic from University of Maryland, College Park, Maryland, for help and suggestions in the preparation of the manuscript.

\section{References}

1. Davies H. Catheter-mounted valve for temporary relief of aortic insufficiency. Lancet. 1965;285:250.

2. Andersen HR, Knudsen LL, Hasenkam JM. Transluminal implantation of artificial heart valves. Description of a new expandable aortic valve and initial results with implantation by catheter technique in closed chest pigs. Eur Heart J. 1992;13:704-8.

3. Cribier A, Eltchaninoff H, Bash A, Borenstein N, Tron C, Bauer F, et al. Percutaneous transcatheter implantation of an aortic valve prosthesis for calcific aortic stenosis: first human case description. Circulation. 2002;106:3006-8.

4. Grube E, Laborde JC, Gerckens U, Felderhoff T, Sauren B, Buellesfeld L, et al. Percutaneous implantation of the CoreValve self-expanding valve prosthesis in high-risk patients with aortic valve disease: the Siegburg first-in-man study. Circulation. 2006;114:1616-24.

5. Lichtenstein SV, Cheung A, Ye J, Thompson CR, Carere RG, Pasupati S, et al. Transapical transcatheter aortic valve implantation in humans: initial clinical experience. Circulation. 2006;114:591-6.

6. Pasic M, Unbehaun A, Dreysse S, Drews T, Buz S, Kukucka M, et al. Transapical aortic valve implantation in 175 consecutive patients: excellent outcome in very high-risk patients. J Am Coll Cardiol. 2010;56:813-20. 
7. Pasic M, Buz S, Dreysse S, Drews T, Unbehaun A, Klein C, et al. Transapical aortic valve implantation in 194 patients: problems, complications, and solutions. Ann Thorac Surg. 2010;90:1463-70.

8. Pasic M, Dreysse S, Drews T, Buz S, Unbehaun A, Kukucka M, et al. Improved technique of transapical aortic valve implantation: "the Berlin addition". Ann Thorac Surg. 2010;89:2058-60.

9. Drews T, Pasic M, Buz S, Unbehaun A, Dreysse S, Kukucka M, et al. Transapical aortic valve implantation after previous heart surgery. Eur J Cardiothorac Surg. 2011;39:625-30.

10. Drews T, Pasic M, Buz S, Unbehaun A, Dreysse S, Kukucka M, et al. Transapical aortic valve implantation after previous mitral valve surgery. $J$ Thorac Cardiovasc Surg. 2011;142:84-8.

11. Pasic M, Unbehaun A, Dreysse S, Buz S, Drews T, Kukucka M, et al. Transapical aortic valve implantation after previous aortic valve replacement: clinical proof of the "valve-in-valve" concept. J Thorac Cardiovasc Surg. 2011;142:270-7.

12. Buz S, Pasic M, Unbehaun A, Drews T, Dreysse S, Kukucka M, et al. Trans-apical aortic valve implantation in patients with severe calcification of the ascending aorta. Eur J Cardiothorac Surg. 2011;40:463-8.

13. Drews T, Pasic M, Buz S, Unbehaun A. Trans-catheter aortic valve implantation after previous aortic homograft surgery. Eur J Cardiothorac Surg. 2011;40:1534-6.

14. Unbehaun A, Pasic M, Buz S, Dreysse S, Kukucka M, Hetzer R, et al. Transapical aortic valve implantation in patients with severely depressed left ventricular function. J Thorac Cardiovasc Surg. 2012;143:1356-63.

15. Unbehaun A, Pasic M, Drews T, Dreysse S, Kukucka M, Hetzer R, et al. Analysis of survival in 300 high-risk patients up to 2.5 years after transapical aortic valve implantation. Ann Thorac Surg. 2011;92:1315-23.

16. Unbehaun A, Pasic M, Dreysse S, Drews T, Kukucka M, Mladenow A, et al. Transapical aortic valve implantation: Incidence and predictors of paravalvular leakage and transvalvular regurgitation in a series of 358 patients. J Am Coll Cardiol. 2012;59:211-21.
17. D'Ancona G, Pasic M, Buz S, Drews T, Dreysse S, Hetzer R, et al. TAVI for pure aortic valve insufficiency in a patient with LVAD. Ann Thorac Surg. 2012;93: e89-91.

18. Pasic M, Dreysse S, Potapov E, Unbehaun A, Buz S, Drews T, et al. Rescue transcatheter aortic valve implantation and simultaneous percutaneous coronary intervention on cardiopulmonary bypass in a patient with an extreme risk profile Heart Surg Forum. 2012;15:e164-6.

19. D’Ancona G, Pasic M, Buz S, Drews T, Dreysse S, Kukucka M, et al. Transapical transcatheter aortic valve replacement in patients with cardiogenic shock Interact Cardiovasc Thorac Surg. 2012;14:426-30.

20. Pasic M, Dreysse S, Unbehaun A, Buz S, Drews T, Klein C, et al. Combined elective percutaneous coronary intervention and transapical transcatheter aortic valve implantation. Interact Cardiovasc Thorac Surg. 2012;14:463-8.

21. Pasic M, Unbehaun A, Dreysse S, Buz S, Drews T, Kukucka M, et al. Rupture of the device landing zone during transcatheter aortic valve implantation: a life-threatening but treatable complication. Circ Cardiovasc Interv. 2012;5: 424-32.

22. Drews T, Pasic M, Buz S, D’Ancona G, Mladenow A, Hetzer R, et al. Elective femoro-femoral cardiopulmonary bypass during transcatheter aortic valve implantation: a useful tool. J Thorac Cardiovasc Surg. 2013;145:757-63.

23. Pasic M, Buz S, Unbehaun A, Hetzer R. Transcatheter aortic valve implantation combined with conventional heart surgery: hybrid approach for complex cardiac features. J Thorac Cardiovasc Surg. 2012;144:728-31.

24. Pasic M, Unbehaun A, Dreysse S, Buz S, Drews T, Kukucka M, et al. Introducing transapical aortic valve implantation (part 1): effect of a structured training program on clinical outcome in a series of 500 procedures. $J$ Thorac Cardiovasc Surg. 2013;145:911-8.

25. Carthey J, de Leval MR, Reason JT. The human factor in cardiac surgery: errors and near misses in a high technology medical domain. Ann Thorac Surg. 2001; $72: 300-5$ 